\title{
REDESAIN RUANG RAMAH ANAK PADA TEMPAT PENITIPAN ANAK GRIYA ANAK SURABAYA
}

\author{
Melania Rahadiyanti ${ }^{1}$, Dyah Kusuma Wardhani ${ }^{2}$, Etha Rambung ${ }^{3}$, Hanna Tabita \\ Hasianna Silitonga ${ }^{4}$ \\ ${ }^{1,2}$ Arsitektur Interior, Universitas Ciputra, Citraland CBD Surabaya \\ ${ }^{3,4}$ Fakultas Kedokteran, Universitas Ciputra, Citraland CBD Surabaya \\ Email Korespondensi: melania.rahadiyanti@ciputra.ac.id
}

Received : June 18, 2020 ; Accepted : July 17, 2020 ; Published : January $1^{\text {st }}, 2021$

\begin{abstract}
Abstrak
Tempat penitipan anak berperan penting bagi tumbuh kembang anak-anak yang berakivitas di dalamnya, karena fungsinya yang utama adalah sebagai tempat bermain dan belajar bagi anak-anak. Penting bagi tempat penitipan anak didesain sesuai dengan kebutuhan akan ruang ramah anak untuk menciptakan kondisi yang nyaman dan aman bagi anak. Pengabdian masyarakat ini ingin terlibat dalam menciptakan ruang ramah anak pada salah satu tempat penitipan anak, yaitu Griya Anak di Surabaya. Kegiatan ini dilakukan dalam beberapa tahap yaitu persiapan berupa observasi lapangan, perencanaan yaitu mendesain ruang yang digunakan sebagai aktivitas utama di Griya Anak, penyuluhan mengenai ruang ramah anak dan diskusi hasil desain, kemudian pelaksanaan berupa menata ulang dan menyediakan perabot yang dibutuhkan untuk menunjang aktivitas di Griya Anak. Hasil kegiatan ini berupa terciptanya desain ruang aktivitas utama di Griya Anak yang lebih nyaman dan aman bagi anak, serta efektif bagi alur aktivitas yang dilakukan para pengurus Griya Anak, serta terpenuhinya kebutuhan akan perabot yang sesuai untuk menunjang kegiatan di Griya Anak.
\end{abstract}

Kata Kunci: kamar ramah anak, lingkungan sehat, tempat penitipan anak

\begin{abstract}
Daycare play an important role in the growth and development of children who are active in it, because its main function is as a place to play and learn for children. It is important that daycare are designed according to the need for child-friendly spaces to create conditions that are comfortable and safe for children. This community service would like to be involved in creating a child-friendly space in one of the daycare, Griya Anak in Surabaya. This activity is carried out in several stages, namely preparation in the form of field observations, planning, namely designing the space used as the main activity in Griya Anak, counseling about child-friendly spaces and discussion of design results, then implementing rearranging and providing furniture needed to support the activities in Griya Anak. The results of this activity include the creation of a main activity space design at Griya Anak that is more comfortable and safer for children, and effective for the flow of activities carried out by the Griya Anak management, as well as the fulfillment of the need for appropriate furniture to support activities at Griya Anak.
\end{abstract}

Keywords : child-friendly room, healthy environment, daycare

\section{Pendahuluan}

Tempat penitipan anak merupakan sarana yang penting untuk mendukung tumbuh kembang anak. Di sini anak akan banyak berinteraksi dengan para pengurus untuk bermain, belajar, dan melakukan kegiatan sehari-hari. Maka dari itu ruangan yang ramah anak pada 
tempat penitipan anak menjadi kebutuhan utama untuk menciptakan lingkungan yang aman, nyaman, dan sehat bagi anak-anak.

Lingkungan ramah anak menurut[1] terdiri dari 3 hal yaitu keamanan, kenyamanan, dan stimulasi pada elemen pembentuk ruang baik ruang luar maupun ruang dalam. Usia 0-6 tahun merupakan golden age untuk anak dan perlu mendapatkan perhatian khusus pada masa tubuh kembangnya, masa menuju proses kematangan fisik dan mental seorang anak untuk menerima dan memberi respons fisik dan mental yang sesuai dari stimulasi yang didapatkan dari lingkungan di sekitarnya. Definisi lain tentang lingkungan ramah anak menurut[2] adalah konsep multidimensional yang kondusif untuk belajar, bermain serta menyediakan fasilitas yang sesuai dengan kebutuhan dan karateristik anak.

Lingkungan yang pertama membentuk perkembangan anak adalah rumah dan lingkungan luar rumah[3]. Rumah sebagai lingkungan pertama yang dikenal oleh anak terdiri dari keluarga dan bangunan fisik yang menaunginya sementara lingkungan luar rumah yang dimaksud di sini dalam bentuk masyarakat maupun lembaga pendidikan/penitipan anak. Setiap kelompok usia memiliki kebutuhan yang berbeda sesuai penggunanya, sehingga lingkungan untuk anak pun membutuhkan penyesuaian terhadap kebutuhan dan perilaku anak.

Kebutuhan akan lingkungan ramah anak pada tempat penitipan anak menjadi sangat perlu untuk dilakukan terutama karena di tempat tersebut anak-anak akan berkumpul dan saling berintreraksi dengan sesama anak, pengajarnya dan dengan lingkungannya, Ruang dalam dapat memanfaatkan elemen interior seperti partisi maupun perabot yang dapat mendukung anak untuk belajar dan bermain[3]. Suasana belajar yang menyenangkan dan dapat memberikan stimulasi untuk anak serta memperhatikan kesehatan dan kenyamanan anak-anak menjadi kata kunci yang perlu untuk diterapkan.

Pengabdian masyarakat untuk mewujudkan ruang ramah anak pada tempat penitipan anak dilakukan kepada tempat penitipan anak sekaligus pendidikan anak usia dini Griya Anak. Griya Anak yang berlokasi di Kecamatan Rungkut, Surabaya ini mengasuh 14 anak berusia dari 3 bulan hingga 5 tahun, yang didampingi oleh 5 orang staf pengurus. Griya Anak didirikan untuk membantu para orang tua bekerja yang membutuhkan pertolongan dalam mengasuh dan mendidik anak-anak mereka.

Berdasarkan hasil observasi, ditemukan beberapa permasalahan pada tempat penitipan anak "Griya Anak", di antaranya pengolahan elemen ruang seperti dinding dan plafon yang kurang ramah untuk anak, penataan perabot interior yang menghalangi sirkulasi udara, dan penataan layout area ruang yang kurang efektif bagi aktivitas anak-anak dan pengurus Griya Anak. Adanya penataan layout ruang yang kurang efektif ini menimbulkan ketidakjelasan penggunaan ruang dan penumpukan barang-barang yang seharusnya area tersebut dapat digunakan untuk beraktivitas bagi para penggunanya. Maka dari itu kegiatan pengabdian masyarakat ini akan menyelesaikan masalah bagaimana desain ruangan yang ramah anak dengan layout ruang yang efektif pada tempat penitipan anak di Griya Anak Surabaya.

\section{Metode}

Pelaksanaan pengabdian masyarakat ini dilakukan dalam empat tahap, sebagai berikut:

1. Tahap persiapan

Tahap awal yaitu melakukan observasi awal dengan menggali kondisi eksisting di Griya Anak, apa saja kebutuhan dan keinginan anak-anak dan pengurus Griya Anak sebagai pengguna ruang. Tahap observasi ini juga bertujuan untuk mengukur ruang yang akan didesain dan kebutuhan perabot yang belum ada dan dibutuhkan pengguna. 


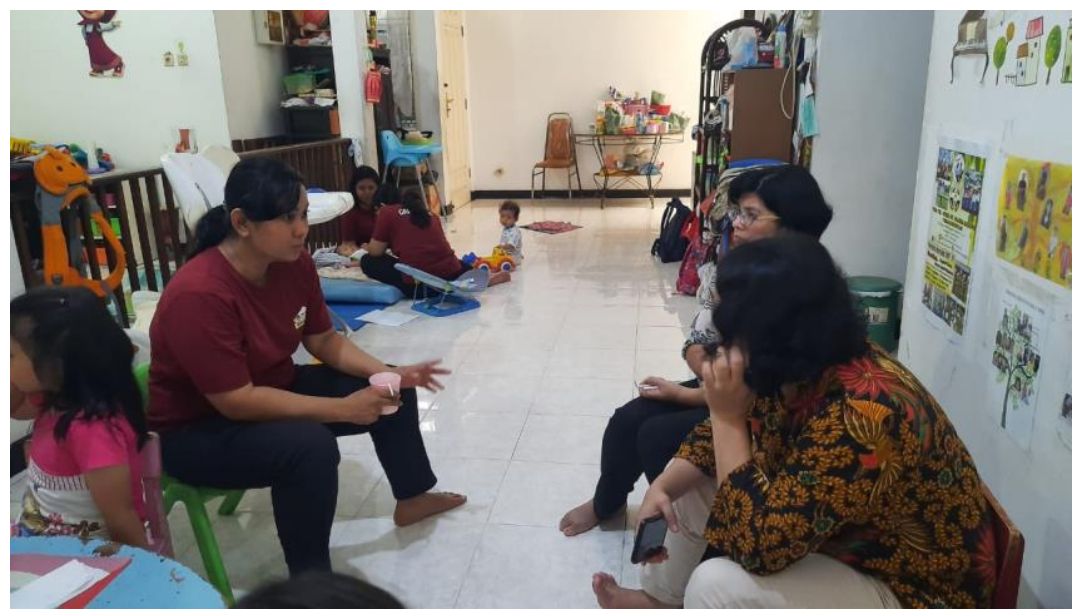

Gambar 1. Kegiatan observasi awal dan interview pengurus Griya Anak

2. Tahap perencanaan

Setelah melakukan observasi kondisi eksisting, proses selanjutnya adalah merencanakan desain interior ruang ramah anak pada Griya Anak. Desain ruang ramah anak ini berdasarkan analisis terhadap kebutuhan pengguna dan kondisi eksisting ruang, kemudian dikaitkan sesuai standar dan kriteria ruang ramah anak.

3. Tahap pelaksanaan

Penyuluhan "Mendesain Interior Ruang Ramah Anak". Penyuluhan dilakukan secara daring menggunakan aplikasi Zoom kepada pengguna ruang yaitu para pengurus Griya Anak. Materi ini dibawakan oleh Melania Rahadiyanti, S.T., M.T. sebagai pembicara. Penyuluhan terdiri dari dua sesi, yaitu:

a. Sesi pertama penyampaian materi prinsip desain ruang ramah anak dan lingkungan sehat. Sesi ini bertujuan untuk mengenalkan hal-hal yang perlu diperhatikan dalam menciptakan ruang yang nyaman dan anak untuk anak.

b. Sesi kedua diskusi redesain ruang Griya Anak. Sesi ini bertujuan menunjukkan hasil desain ulang beberapa ruang yang ada di Griya Anak sehingga lebih aman dan nyaman.

4. Penerapan desain interior ruang ramah anak pada Griya Anak dengan membantu menata ulang ruang aktivitas utama dan menyediakan perabot untuk menunjang aktivitas anak dan pengurus Griya Anak. 


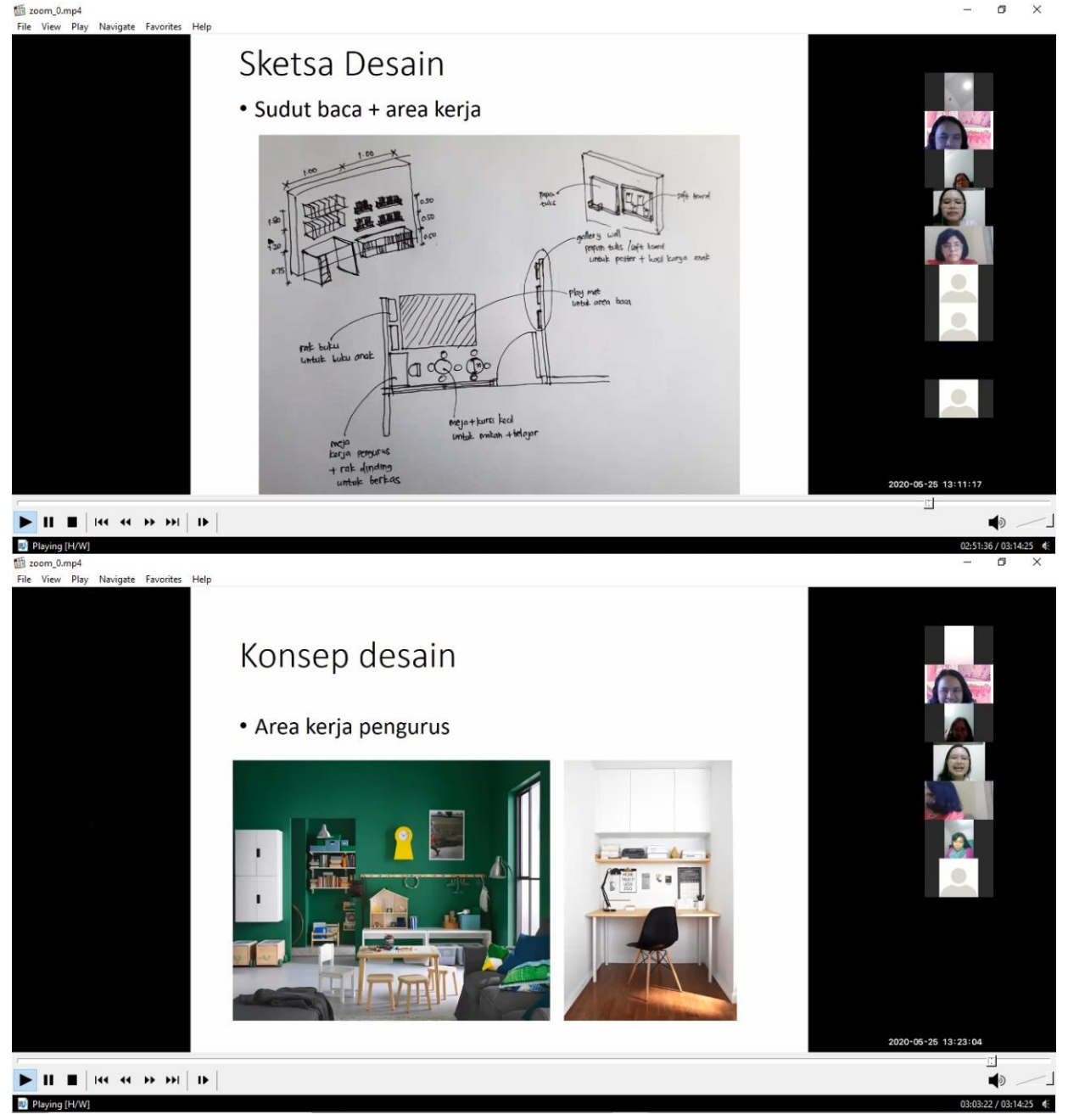

Gambar 2. Rekaman kegiatan penyuluhan secara daring dengan pengurus Griya Anak

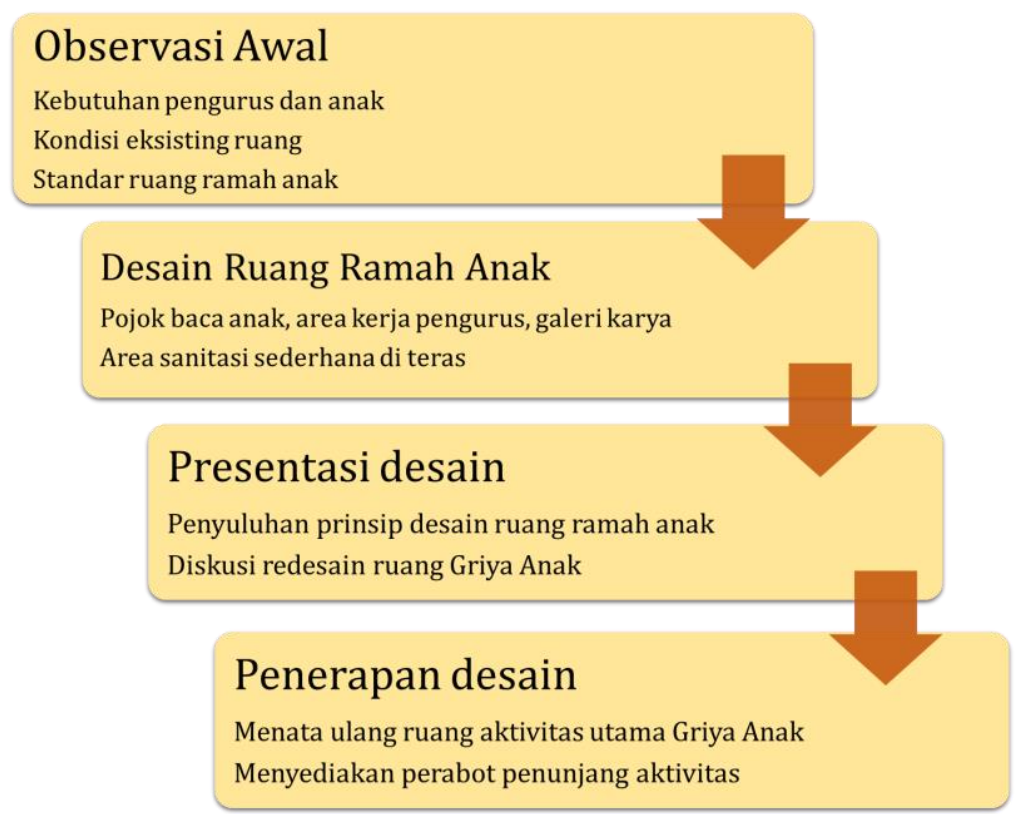

Gambar 3. Kerangka konseptual penyelesaian masalah ruang ramah anak di Griya Anak 


\section{Hasil dan Pembahasan}

Kriteria lingkungan ramah anak menurut[2] adalah berpusat pada anak, aman, sehat, melindungi dan memberikan stimulasi. Redesain ruang penitipan anak ini memperhatikan kriteria tersebut dalam beberapa strategi yang dapat dijelaskan sebagai berikut:

- Berpusat pada anak

Berpusat pada anak dengan menyesuaikan antropometri tubuh anak pada fungsi ruangan dan pemilihan furniture untuk anak. Agar lingkungan anak dapat meberikan kenyamanan kepada anak perlu untuk memperhatikan antropometri anak usia praskolah, rentang jangkauan tubuh anak, serta ergonomi furniture. Ukuran dari furniture anak disesuaikan dengan pelaksanaan aktivitas bermain dan belajar anak, rata-rata tinggi badan anak usia 4 tahun adalah 103.5-108 cm, tinggi badan anak berusia 5 tahun adalah $109 \mathrm{~cm}$.

Tabel 1. Ukuran tubuh anak dan bentangan furniture yang dibutuhkan[4]

\begin{tabular}{|c|c|c|c|c|c|c|c|}
\hline & & Besar & $\begin{array}{l}\text { Rata } \\
\text { Rata }\end{array}$ & - Kecil & & Besar & $\begin{array}{ll}\text { Rata - Kecil } \\
\text { Rata }\end{array}$ \\
\hline A & High reach & 133 & 121 & 108,5 & $\mathrm{~J}$ & Work top & 57 \\
\hline B & Low reach & 50 & 46,5 & 42,5 & $\mathrm{~K}$ & Work depth & 33 \\
\hline C & Reach distance & 48 & 43,5 & 86,5 & $\mathrm{~L}$ & Table height & 44,5 \\
\hline $\mathrm{D}$ & High reach & 97 & 91,5 & 34,5 & $\mathrm{M}$ & Seat height & 26,5 \\
\hline E & Reach radius & 43 & 38,5 & 72 & $\mathrm{~N}$ & Seat to backrest & 12 \\
\hline $\mathrm{F}$ & Eye level & 81,5 & 77 & - & 0 & Backrest height & 12,5 \\
\hline G & Shelf height & & 109 & & $\mathrm{P}$ & Armrest spacing & 30,5 \\
\hline $\mathrm{H}$ & Lavatory height & & 48,5 & & $Q$ & Seat width & 28 \\
\hline
\end{tabular}

- Aman

Aman pada lingkungan anak didefinisikan dengan kondisi lingkungan yang bebas dari resiko anak cedera dan mengalami luka fisik saat beraktivitas. Beberapa hal yang perlu diperhatikan untuk faktor aman ini adalah pencapaian menuju bangunan, permukaan material serta dimensi dari elemen-elemen yang ada pada ruang. Aman pada redesain ruang penitipan anak ini dengan menambahkan finishing 3D foam wall panel untuk memberikan perlindungan ekstra pada pergerakan anak yang aktif.

- Sehat dan melindungi

Kesehatan sebagai kondisi yang bebas dari gangguan jasmani, rohani maupun sosial yang disebabkan oleh lingkungan, sehingga kesehatan pada lingkungan anak adalah kondisi yang bebas dari gangguan untuk membahayakan keadaan fisik anak yang sehat.

Dalam penitipan anak ini dilakukan dalam bentuk memilih bahan furniture dan material finishing ruang yang ramah lingkungan, tidak mengandung VOC, formaldehyde atau bahan kimia lain yang berbahaya. Dalam rangka menjaga kebersihan dan kesehatan anak terutama di masa new normal ini, penyediaan area untuk cuci tangan juga ditambahkan pada teras untuk menanamkan kebiasaan menjaga kebersihan sebelum beraktivitas.

- Memberikan stimulasi

Stimulasi pada lingkungan ramah anak adalah sebuah cara untuk menciptkan lingkungan yang dapat memberikan rangsangan untuk mengeskplorasi kejadiankejadian di sekitarnya. Stimulasi untuk anak perlu karena menjadi rangsangan bagi anak untuk memberikan respons perilaku dan memicu kreativitas. Stimulasi harus sesuai, tidak kurang dan juga tidak berlebihan, untuk ruang anak stimulasi dapat dimunculkan melalui pemilihan warna yang dipakai pada ruang. Stimulasi dapat dilakukan dalam bentuk 3 hal yaitu stimulasi spasial dan visual. Menurut[5], penggunaan dominasi dari kelompok warna hangat (warm colors) dengan variasi value dan intensity dapat menstimulasi anak untuk lebih semangat bila dibandingkan dengan kelompok warna yang lebih sejuk (cool colors). 

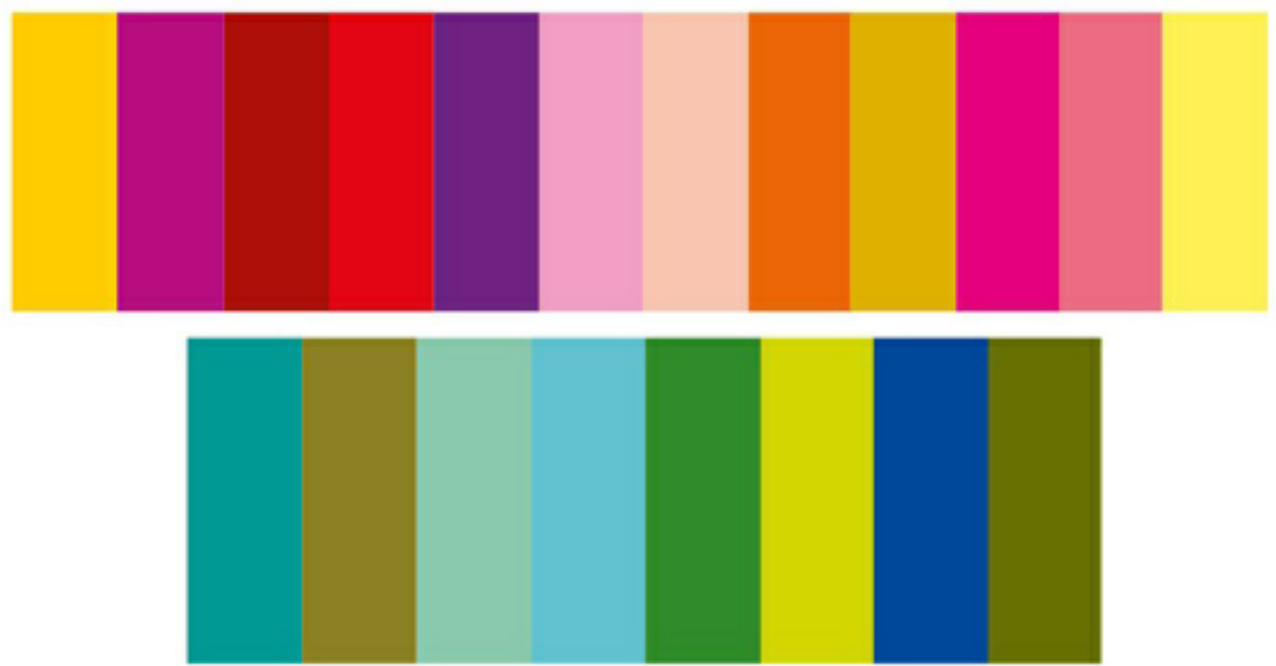

Gambar 4. Warm colors (atas) dan cool colors (bawah)

Desain ruang ramah anak di Griya Anak direncanakan pada ruang yang paling banyak dilakukan aktivitas bersama antara anak-anak dengan para pengurusnya. Konsep desain yang diterapkan yaitu menata letak perabot dan peralatan agar tercipta tata letak yang bersih dan jelas di ruang tersebut bagi para pengurus dan anak-anak di Griya Anak. Pada kondisi eksisting, permasalahan yang terjadi di ruang ini belum tertata dengan jelas pembagian areanya, sehingga menimbulkan kesulitan bagi pengurus untuk meletakkan peralatan kerjanya dan area anak-anak untuk makan dan bermain menjadi terbatas.

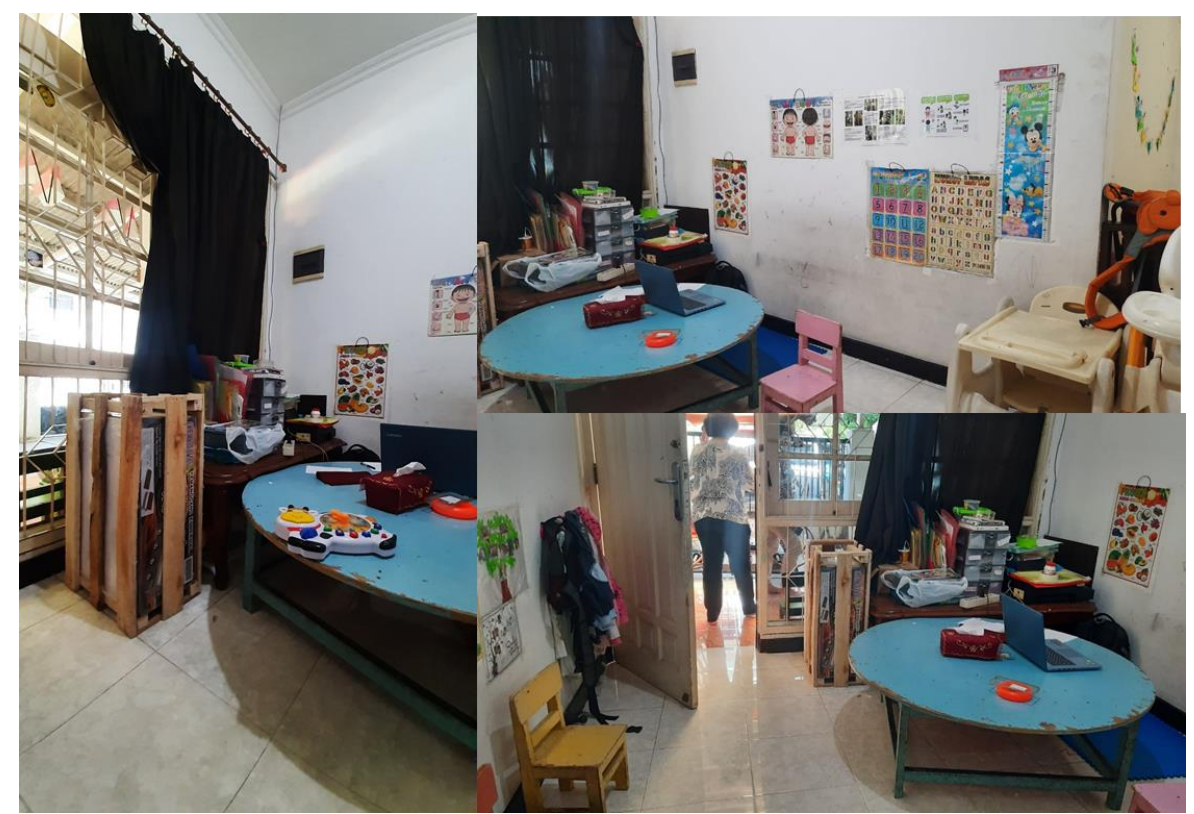

Gambar 5. Kondisi eksisting area kerja pengurus, area membaca dan bermain, serta area makan untuk anak-anak di Griya Anak.

Menanggapi permasalahan pada kondisi eksisting, maka aplikasi konsep desain pada Griya Anak untuk menata letak perabot dan peralatan ruangan agar lebih bersih dan jelas, dilakukan sebagai berikut:

- Membagi area kerja pengurus, area membaca dan bermain, dan area makan menjadi tiga zona sesuai fungsinya dan memilih perabot yang aman dan sesuai dengan kebutuhan area tersebut 
- Memilih dan meletakkan perabot di area yang dekat dengan jendela dan pintu sehingga tidak menghalangi masuknya udara dan sinar matahari ke dalam ruangan sehingga sirkulasi udara dapat terjaga dan pencahayaan cukup untuk melakukan aktivitas bagi pengguna.

Area kerja pengurus, area membaca dan bermain, serta area makan akan menempati area eksisting yang sudah digunakan saat ini sesuai fungsi tersebut, penyesuaian dilakukan dengan menata ulang dan membagi area tersebut agar alur kegiatan menjadi lebih jelas dan mudah dibersihkan. Area kegiatan utama ini dibagi menjadi beberapa zona yaitu:

- Area makan untuk anak, area ini diletakkan dekat jendela, karena perabot yang digunakan mempunyai tinggi yang rendah dan tidak menghalangi tinggi jendela yang harus dibuka. Selain itu pemilihan kursi dan meja mekan untuk anak-anak disesuaikan dengan ukuran yang tidak terlalu besar, sehingga mudah jika dipindah dan sirkulasi pengguna di ruangan tetap nyaman.

- Area kerja untuk pengurus, menggunakan meja dan kursi kerja yang berukuran compact, karena kebutuhan kerja tidak terlalu banyak, cukup untuk satu orang pengurus yang bekerja di area ini. Storage untuk dokumen diletakkan pada rak dinding untuk menghemat ruang dan diletakkan pada ketinggian tertentu sehingga jauh dari jangkauan anak-anak.

- Area baca untuk anak-anak, menggunakan storage rendah yang mudah dijangkau anak-anak dan rak dinding untuk display buku. Di area baca bisa diletakkan play mat untuk anak-anak bisa duduk di lantai. Rak dinding yang digunakan dipilihkan yang dapat memperlihatkan sampul buku anak-anak sehingga memudahkan anak-anak untuk memilih buku yang ingin dibaca.

- Area display karya anak-anak di samping pintu masuk. Pada area ini dapat diletakkan white board dan soft board untuk menempelkan poster edukasi atau hasil karya anakanak agar mudah dilihat oleh anak-anak dan pengurus.

- Dalam redesain tempat penitipan anak ini menggunakan stimulasi spasial warna yang memberi rangsangan positif kepada anak dalam bentuk pemilihan warna 3D foam wall panel. 3D foam wall panel ini juga berfungsi sebagai pengaman ketika badan anak terbentur dinding di sekitar ruang aktivitas utama karena teksturnya yang tebal dan terbuat dari bahan yang lembut. 


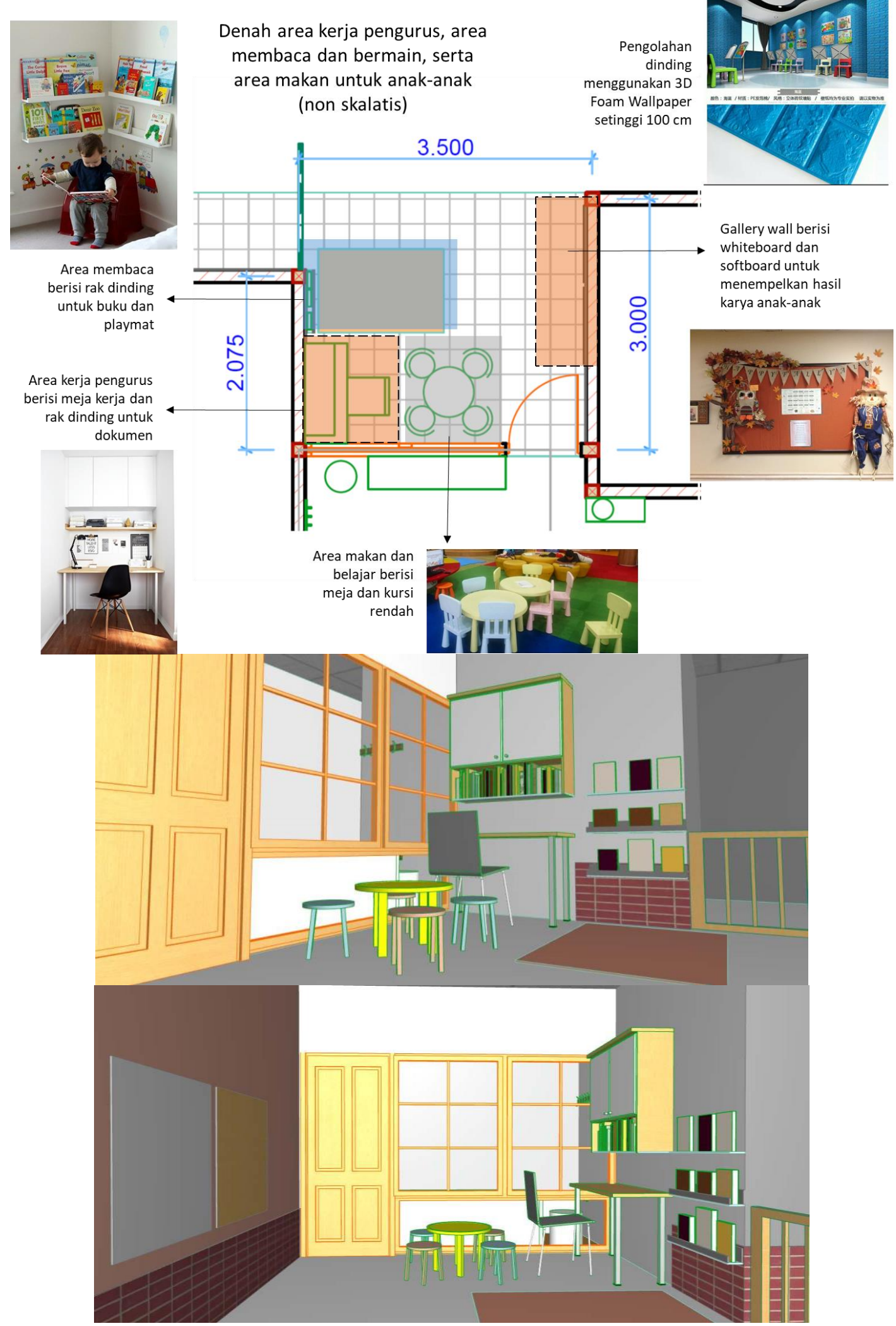

Gambar 6. Desain area kerja pengurus, area membaca dan bermain, serta area makan untuk anak-anak di Griya Anak 


\section{Kesimpulan}

Kegiatan pengabdian masyarakat dengan mitra Griya Anak ini menghasilkan beberapa output yaitu:

1. Terciptanya desain ruang aktivitas utama di Griya Anak yang lebih nyaman dan aman bagi anak, menjaga sirkulasi udara tetap mengalir melalui bukaan yaitu dengan mendesain area bukaan tidak terhalang perabot dan peralatan, serta efektif bagi alur aktivitas yang dilakukan para pengurus Griya Anak.

2. Terpenuhinya kebutuhan akan perabot yang sesuai untuk menunjang kegiatan di Griya Anak.

\section{Daftar Pustaka}

[1] Diyanti, A. O., Amiuza, C. B., dan Mustikawati, T., "Lingkungan Ramah Anak pada Sekolah Taman Kanak-Kanak", Review of Urbanism and Architectural Studies, vol 12, no. 2, pp. 54-68, 2014. https://doi.org/10.21776/ub.ruas.2014.012.02.6

[2] UNICEF. The Child Friendly School manual, pp. 1-244, 2006. http://www.unicef.org/publications/files/Child_Friendly_Schools_Manual_EN_04080 $\underline{\text { 9.pdf }}$

[3] Sriti Mayang Sari, "Peran Warna Interior Terhadap Perkembangan Dan Pendidikan Anak Di Taman Kanak-Kanak", Dimensi Interior, vol. 2, no. 1, 22-36, 2004. http://puslit2.petra.ac.id/ejournal/index.php/int/article/view/16244

[4] Ramsey, Architectural Graphic Standards, New York: John Wiley \& Sons, Inc, 1994.

[5] Kopacz, J, Color in three-dimensional design, McGraw Hill Professional, 2004.

[6] Evans, G.W. and McCoy, J.M., "When buildings don't work: The role of architecture in human health", Journal of Environmental psychology, vol 18, no. 1, pp. 85-94, 1998.

[7] Kementerian Pendidikan Nasional, Peraturan Menteri Pendidikan Nasional No. 58 Tahun 2009 Tentang Standar Pendidikan Anak Usia Dini. Jakarta: Sekretariat Negara, 2009.

[8] Perehudoff, B.E., Parents' perceptions of environmental stressors in the special care nursery, (Doctoral dissertation, University of British Columbia), 1987.

[9] Satwiko, P., Fisika Bangunan. Yogyakarta: Andi, 2004.

[10] Satwiko, P., Arsitektur Sadar Energi. Penerbit Andi, Yogyakarta, 2005.

[11] Sun, Y. and Sundell, J., "Early daycare attendance increase the risk for respiratory infections and asthma of children", Journal of Asthma, vol. 48, no. 8, pp.790-796, 2011.

[12] Trancik, A.M. and Evans, G.W., "Spaces fit for children: Competency in the design of daycare center environments", Children's Environments, pp. 311-319, 1995. 
Melania Rahadiyanti, Dyah Kusuma Wardhani, Etha Rambung, Hanna Tabita Hasianna Silitonga 